\title{
Experimental study on partial compression parallel to grain of solid timber
}

\author{
Marina Totsuka ${ }^{1 *}$ (D), Robert Jockwer ${ }^{2} \mathbb{D}$, Kenji Aoki ${ }^{1}$ (I) and Masahiro Inayama ${ }^{1}$
}

\begin{abstract}
This paper describes results and analysis of experimental testing of entire and partial compression strength and stiffness parallel to the grain of solid timber (Japanese cedar). To investigate the spreading effects, the size effect of strength and stiffness, and the mechanism of the damage zone located close to the loading plates, tests on 90 specimens were performed. As a result, it was observed that damage zones existed near the loading plates. The observed spreading effects in the compression parallel to the grain were very small which justifies neglecting them regarding strength and stiffness. Although a presence of a size effect of the compression strength parallel to the grain of glulam specimens with knots was reported, the compression strength parallel to the grain of solid wood specimens without knots does not have a size effect. The height and width of the cross-section of the specimens have an influence on the damage zones and, hence, on the effective modulus of elasticity of the full height of the specimens. The compression strength has a correlation with the density of the timber and the width of the annual rings.
\end{abstract}

Keywords: Timber, Compression parallel to grain, Damage zone, Size effect, Modulus of elasticity parallel to grain, Spreading effect

\section{Introduction}

In timber buildings, deformations often concentrate on connections that have to be taken into account in the design. In the connections, the timber is often loaded in partial compression parallel to the grain, e.g., a tensile bolt connection (see Fig. 1) which is often used in Japan. Because the deformations under compression perpendicular to the grain are larger than the deformations under compression parallel to the grain by anisotropy of wood, the deformations under compression parallel to the grain are often ignored. However, in recent years, the number of high-rise timber buildings has increased, which urges the need to consider the deformation under compression parallel to the grain also in these buildings.

Partial compression parallel to the grain was studied by Noguchi et al. [1]. Though they proposed a theoretical

\footnotetext{
*Correspondence: t.marina010@gmail.com; mtotsuka@chiba-u.jp

${ }^{1}$ Department of Biomaterials Sciences, Graduate School of Agricultural and Life Sciences, The University of Tokyo, 1-1-1 Yayoi, Bunkyo-ku, Tokyo, Japan

Full list of author information is available at the end of the article
}

evaluation method with a spreading effect, the impact of the spreading effect of real wood specimens was not clear.

The compression strength parallel to the grain of largescale specimens of glulam (glued laminated timber) is presented by Fryer et al. [2]. The report presented the presence of a size effect of the glulam specimens and the size effect was much greater lengthwise than width-wise.

The heterogeneity of the strains in members loaded in compression parallel to the grain was reported in papers (Choi et al. [3] and Dahl and Malo [3]). It is observed that the largest strains are allocated near the loading plates (Zink et al. [5]), which create a zone often called the "damage zone". The zone between these damage zones is referred to as the "middle zone". Xavier et al. [6] and Martin et al. [7] investigated the behavior of the damage zones, e.g., the length and the modulus of elasticity, in small clear specimens.

In this present work, the partial compressive property parallel to the grain was investigated using solid timber of

\section{Springer Open}

(c) The Author(s) 2021. This article is licensed under a Creative Commons Attribution 4.0 International License, which permits use, sharing, adaptation, distribution and reproduction in any medium or format, as long as you give appropriate credit to the original author(s) and the source, provide a link to the Creative Commons licence, and indicate if changes were made. The images or other third party material in this article are included in the article's Creative Commons licence, unless indicated otherwise in a credit line to the material. If material is not included in the article's Creative Commons licence and your intended use is not permitted by statutory regulation or exceeds the permitted use, you will need to obtain permission directly from the copyright holder. To view a copy of this licence, visit http://creativeco mmons.org/licenses/by/4.0/. 


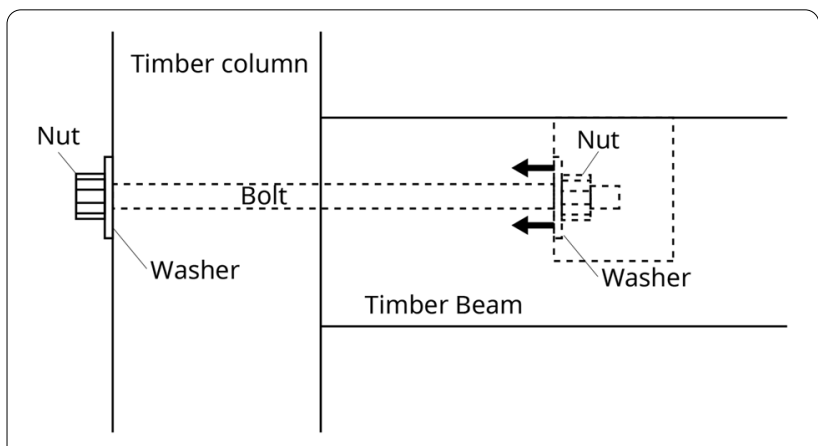

Fig. 1 Tensile bolt connection with partial compressive resistance

Japanese cedar (Cryptomeria japonica). The aims of this work are as follows:

(1) to evaluate the spreading effects of partial compression parallel to the grain.

(2) to study the relationship between dimensions of specimens and the compression strength and stiffness reduction.

\section{Materials and methods}

\section{Specimens}

Table 1 shows an overview of the test series of solid timber specimens. The specimens of each of the 15 series were cut from one piece of solid wood of Japanese cedar (Cryptomeria japonica). From 6 pieces of kiln-dried solid wood, a total of 90 specimens were prepared by manufacturing 6 specimens per series. After cutting, the specimens were stored in open indoor climate air for several weeks. Before the tests, these specimens were conditioned in an environmental chamber with a temperature of $20{ }^{\circ} \mathrm{C}$ and relative humidity of $65 \%$ during a week. The test parameters are the type of test setup and the size of the specimens.

The actual dimensions and weight of each specimen were measured before testing. The moisture content of specimens after the testing was $11.0-13.8 \%$, determined by the oven-dry method. The density of specimens measured immediately before the testing was $321-552 \mathrm{~kg} / \mathrm{m}^{3}$ when the moisture content was $11.0-13.8 \%$.

Three types of the test setup, as shown in Fig. 2, were used to investigate the spreading effects of partial compression. The specimens were loaded monotonically in compression parallel to the grain. The series "entire surface" were specimens loaded on the entire surface that did not have any visible defects (knots or cracks). The series "partial 1 and 2" are the specimens loaded on the partial surface that had no defects around the loaded surface either.

\section{Test methods}

The compression tests of the specimens with the loaded cross-section of $30 \times 30 \mathrm{~mm}^{2}$ were carried out on an Instron testing machine with an in-line $100-\mathrm{kN}$ load cell under displacement controlled loading at a rate of $0.3 \mathrm{~mm} / \mathrm{min}$. The compression tests of the specimens

Table 1 Overview of test series of solid timber specimens

\begin{tabular}{|c|c|c|c|c|c|c|c|c|}
\hline \multirow[t]{2}{*}{ Series } & \multirow[t]{2}{*}{ Number } & \multirow[t]{2}{*}{ Test setup } & \multicolumn{2}{|c|}{$\begin{array}{l}\text { Specimen size } \\
{[\mathrm{mm}]}\end{array}$} & \multirow[t]{2}{*}{ Loaded area $[\mathrm{mm}]$} & \multirow[t]{2}{*}{$\begin{array}{l}\text { Average distance of } \\
\text { annual rings [mm] }\end{array}$} & \multirow[t]{2}{*}{ Density $[\mathrm{kg} / \mathrm{m}]$} & \multirow{2}{*}{$\begin{array}{l}\text { Average } \\
\text { moisture } \\
\text { content [mm }\end{array}$} \\
\hline & & & Cross sect & & & & & \\
\hline $3-3$ & 6 & Entire surface & $30 \times 30$ & 30 & $30 \times 30$ & 5.2 & 411 & $11.0-13.8$ \\
\hline $3-6$ & 6 & & & 60 & & 4.7 & 399 & \\
\hline $3-9$ & 6 & & & 90 & & 4.6 & 394 & \\
\hline $6-3$ & 6 & & $60 \times 60$ & 30 & $60 \times 60$ & 4.3 & 411 & \\
\hline $6-6$ & 6 & & & 60 & & 5.2 & 400 & \\
\hline $6-9$ & 6 & & & 90 & & 4.6 & 411 & \\
\hline $9-3$ & 6 & & $90 \times 90$ & 30 & $90 \times 90$ & 4.7 & 418 & \\
\hline $9-6$ & 6 & & & 60 & & 4.8 & 404 & \\
\hline $9-9$ & 6 & & & 90 & & 4.8 & 459 & \\
\hline $3-9 p$ & 6 & Partial 1 & $30 \times 90$ & 90 & $30 \times 30$ & 5.3 & 416 & \\
\hline $6-9 p$ & 6 & & $60 \times 120$ & 90 & $60 \times 60$ & 5.4 & 406 & \\
\hline $9-9 p$ & 6 & & $90 \times 120$ & 90 & $90 \times 90$ & 5.1 & 406 & \\
\hline 3-9pp & 6 & Partial 2 & $120 \times 120$ & 90 & $30 \times 30$ & 6.2 & 401 & \\
\hline 6-9pp & 6 & & & 90 & $60 \times 60$ & 6.3 & 408 & \\
\hline 9-9pp & 6 & & & 90 & $90 \times 90$ & 5.2 & 407 & \\
\hline
\end{tabular}



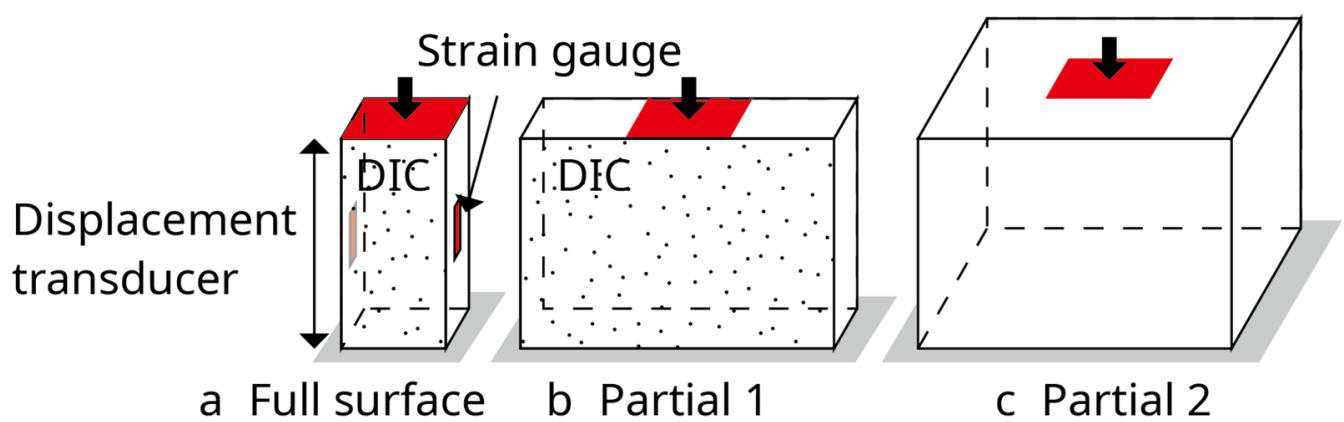

c Partial 2

Fig. 2 Test setup of solid timber specimens

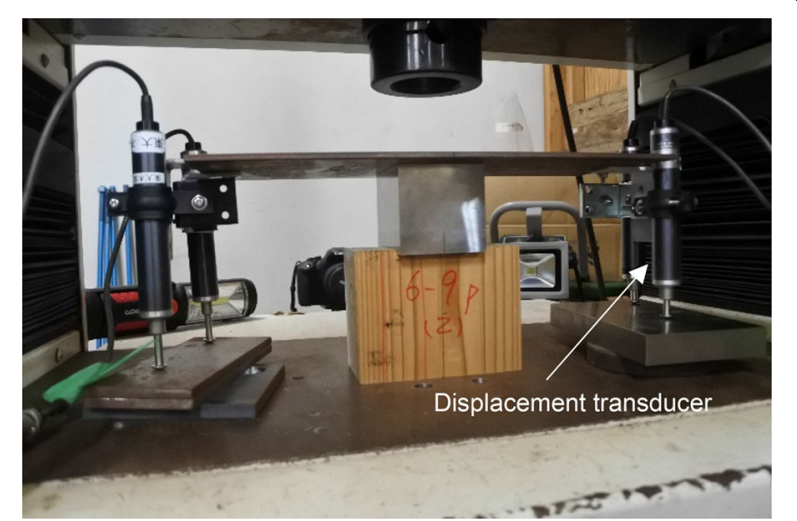

Fig. 3 Test measurements of solid timber specimen (6-9p in Table 1)

with the loaded cross-section of $60 \times 60 \mathrm{~mm}^{2}$ and $90 \times 90 \mathrm{~mm}^{2}$ were carried out on a testing machine with a 500-kN load cell under displacement controlled loading at a rate of $0.3 \mathrm{~mm} / \mathrm{min}$. In all the tests, the tests were stopped after loading drop to $80 \%$ of a maximum load and a displacement transducer $(50 \mathrm{~mm}$ measurement length) was attached to measure loading plate movement as shown in Fig. 3. For the series "entire surface", strain gauges were attached to two faces to measure the deformations of the middle zone; see Fig. 2. For the series "entire surface" and series "partial 1", the 2D digital image correlation (DIC) system was used to record the strain of a side of the specimens. A 2D optical system captured images at a frequency of $0.2 \mathrm{~Hz}$ during testing. The images were processed with the DIC software, GOM correlate, GOM Gmbh (Braunschweig, Germany) [8]. This software uses an automated computer algorithm to determine local displacements and strains according to deformation images.

\section{Test results and discussion}

\section{Stress-strain curves and failure mechanisms}

The stress $\left(\sigma_{c}\right)$ and strain $(\varepsilon)$ were calculated from Eq. 1 and Eq. 2:

$$
\begin{aligned}
& \sigma_{c}=\frac{P}{A}, \\
& \varepsilon=\frac{\Delta l}{H},
\end{aligned}
$$

where $P$ is the applied compression load measured by the load cell of the testing machine, $A$ is the loaded area of the specimens, $\Delta l$ is the average of the deformation in the full height of the specimens measured by the four displacement transducers and $H$ is the initial height of the specimens.

Figure 4 shows the stress $\left(\sigma_{c}\right)$-strain $(\varepsilon)$ curves of the specimens. The stress $\left(\sigma_{c}\right)$-strain $(\varepsilon)$ curves have initial slip because a contact surface with the loading plate was flattened in all specimens. In the results of the series "entire surface" (no. 3-3, 3-6, 3-9, 6-3, 6-6, 6-9, 9-3, 9-6 and 9-9 in Table 1), the stress gradually decreased after maximum stress. In the results of the series "partial 2" (no. 3-9, 6-9 and 9-9pp in Table 1), the stress decreased a little after the maximum stress. After that, the stress stayed on a plateau. This may be related to the fact that the series "entire surface" not only deformed under loading plates, but also largely kinked on the middle zone (Fig. 5(a)); however, the series "partial 2" deformed only under the loading plate (Fig. 5(b)) after the maximum stress. The results of the series "partial 1" show a mix of these phenomena.

\section{Damage zone}

The strain distributions recorded by DIC showed the damage zones in the upper and lower side of the specimens as shown in Fig. 6. In the damage zone, the absolute value of strain exponentially increased as the distance from the loading plate decreased. Figure 7 shows the strain distributions of specimen no. 3-9 in the damage zone at each load. The lengths of the damage zone at each load were approximately the same. The highest absolute value of strain increased as the load increased. The stiffness in full height was a constant value, however, the strains in the damage zone were 


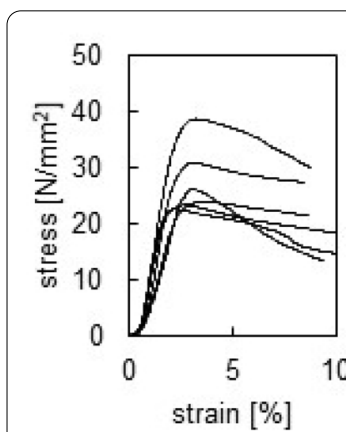

a $3-3$
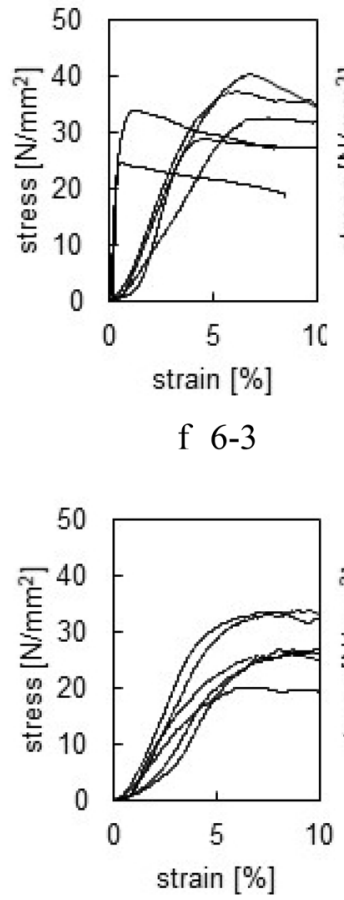

k 9-3

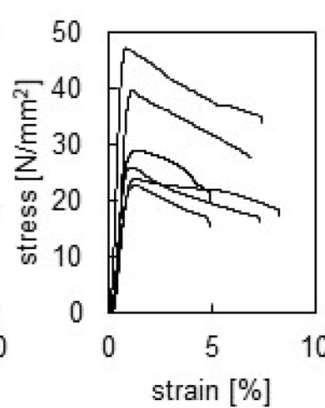

b 3-6

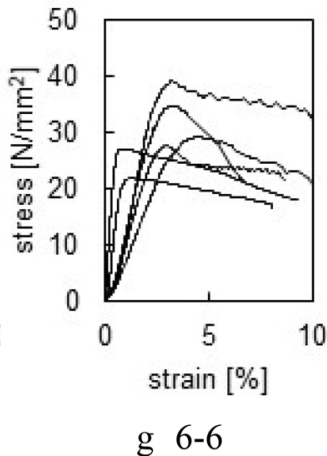

g 6-6

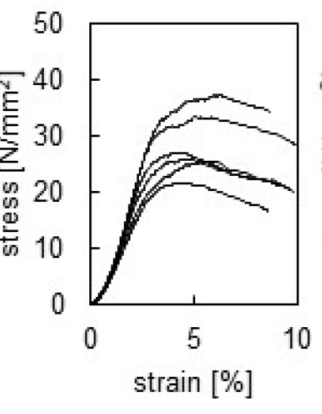

$19-6$

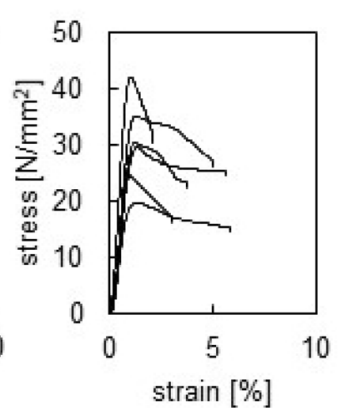

c 3-9

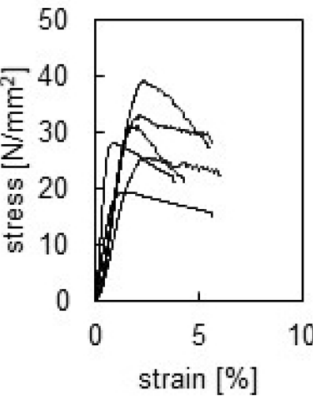

h $6-9$

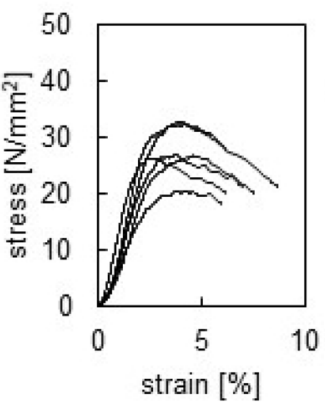

m 9-9
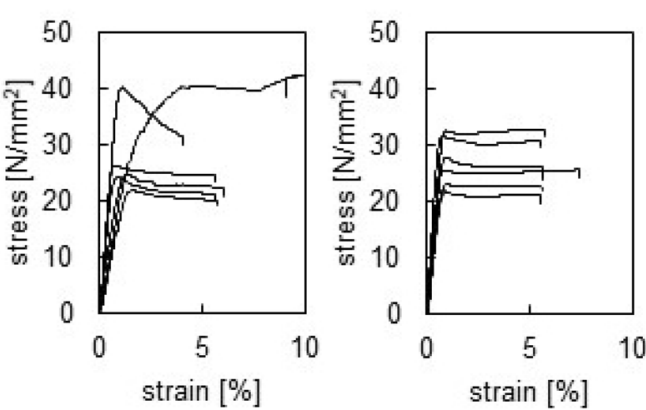

d 3-9p

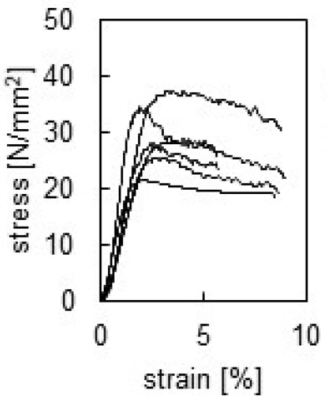

i $6-9 p$

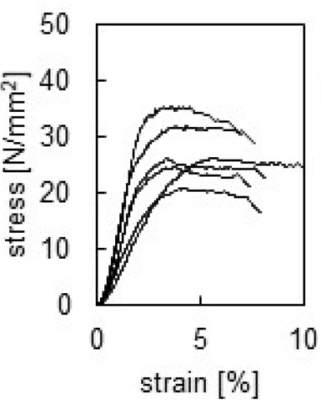

n $9-9 p$ e $3-9 p p$
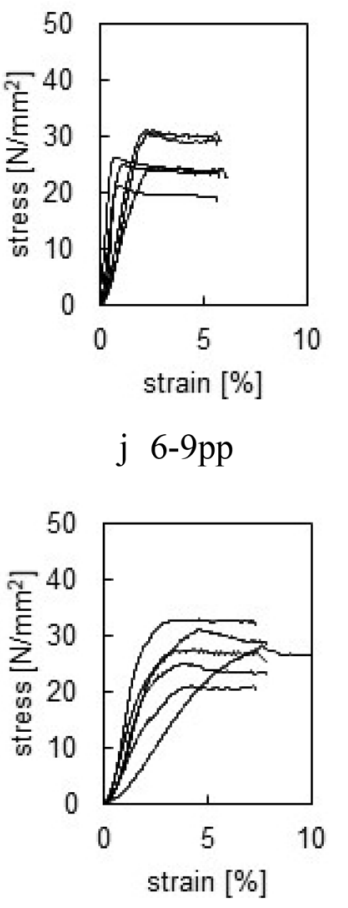

o $9-9 p p$

Fig. 4 Stress-strain curves of specimens

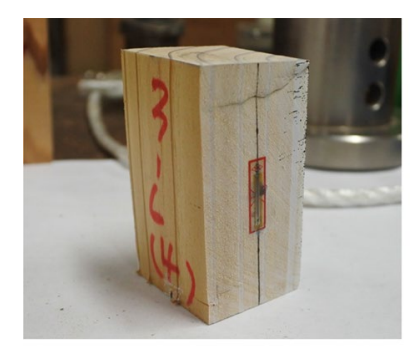

a $3-6$

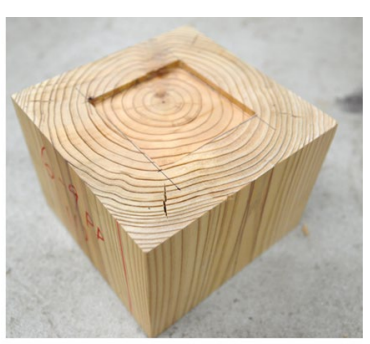

b 6-9pp
Fig. 5 Typical failure mechanisms: (a) large kinking, (b) compressive failure only under loading plate high level in $0.2 P_{\max }-0.6 P_{\max }\left(P_{\max }\right.$ : the maximum load $)$ as shown in Fig. 7. Though there is a possibility that the damage zone was in the plastic state in $0.2 P_{\max }-$ $0.6 P_{\max }$, details of the phenomenon of the damage zone are still unclear and it is a subject of future study. The other specimens also had the same trend. Though strains around the loading plate could not be measured accurately, the length of the damage zone was about $1-4 \mathrm{~mm}$ and had a tendency to increase as the crosssectional area increase. To measure the length of the damage zone accurately by DIC, we need to make the smaller random pattern and paint the loading plate as well. 


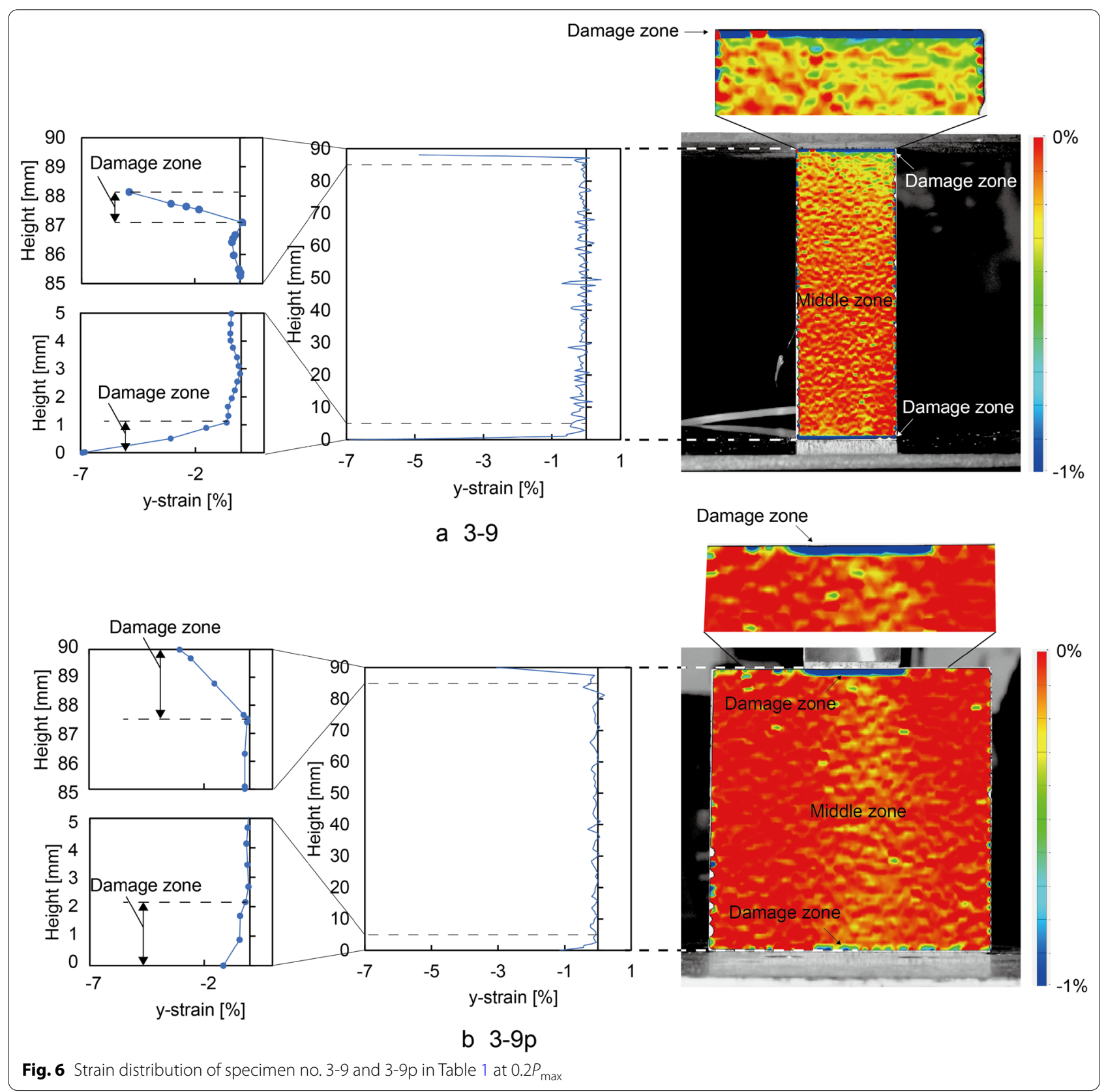

\section{Evaluation of the maximum stress and the modulus of elasticities}

The compression strength (maximum stress) was calculated as the ratio between the maximum load $\left(P_{\max }\right)$ and the loaded area of the specimens $(A)$ :

$$
f_{c, 0}=\frac{P_{\max }}{A} .
$$

According to the equilibrium and linear elastic constitutive equations, the following closed-form solution can be obtained for the identification of the longitudinal modulus of elasticity:

$$
E_{L}=\frac{P}{A \varepsilon_{1}},
$$

where $P$ is the applied compression load and $\varepsilon_{1}$ is the linear strain along the longitudinal direction. In this study, two types of the $E_{L}$ were calculated: (1) the longitudinal modulus of elasticity in full height $\left(E_{L, f}\right)$ using the $\varepsilon_{1}$ in the full height of the specimens measured by the displacement transducers, (2) the longitudinal modulus of elasticity in the middle zone $\left(E_{L, \mathrm{~m}}\right)$ using the $\varepsilon_{1}$ in the middle zone measured by the strain gauges. 

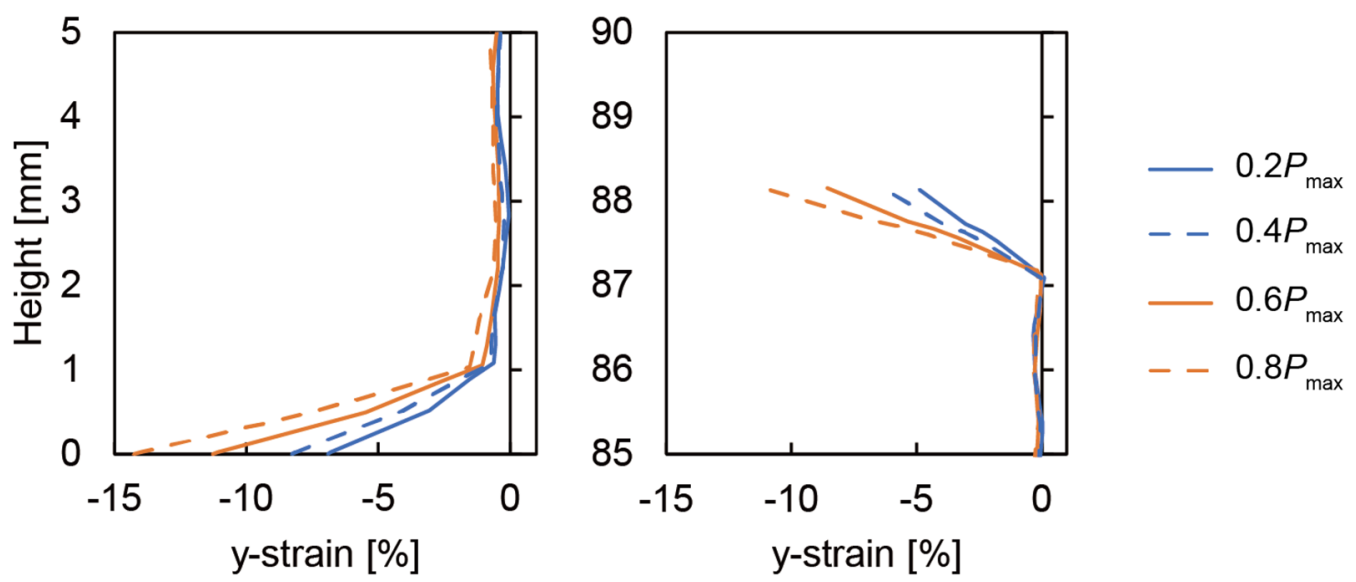

Fig. 7 Strain distribution of specimen no. 3-9 in damage zone at each load

\section{Density and width of annual rings}

Figure 8 shows the $f_{c, 0}$ against the density and width of annual rings in all specimens. The value of $f_{c, 0}$ increases as the density increases, whereas the value of $f_{c, 0}$ decreases as the width of annual rings increases. The values of $E_{L, f}$, of all series and $E_{L, \mathrm{~m}}$ of the series "entire surface" do not have a strong correlation with the density and width of annual rings; see Fig. 9.

\section{Spreading effects}

Table 2 contains statistics of all series. Specimens loaded in compression perpendicular to the grain show pronounced spreading effects of stresses as discussed, e.g., by Leijten et. al. [9] and van der Put [10]. The stress spreading $\left(k_{c}\right)$ is given by Eq. 5 :

$$
k_{c}=\frac{f_{c, s}}{f_{c}},
$$

where $f_{c, \mathrm{~s}}$ is compression strength loaded on the partial surface and $f_{c}$ is compression strength loaded on the entire surface in the same loaded area. In addition, the ratio of longitudinal modulus of elasticity in full height can be given by Eq. 6 :

$$
k_{E}=\frac{E_{L, \mathrm{f}, \mathrm{s}}}{E_{L, \mathrm{f}}}
$$

where $E_{L, \mathrm{f}, \mathrm{s}}$ is the longitudinal modulus of elasticity loaded on the partial surface and $E_{L, \mathrm{f}}$ is the longitudinal modulus of elasticity loaded on the entire surface in the same loaded area. The values of $k_{c}$ were $0.9-1.0$ and $k_{E}$ were 1.0-1.1 in this study; see Table 2 . It indicates that the spreading effects in the compression parallel to the grain are small enough to be ignored for $f_{c, 0}$ and $E_{L, \mathrm{f}}$. The reasons were considered that kinking failure occurs under the loading plates in the series "partial 1 and partial 2" and the effective cross-sectional area was the size
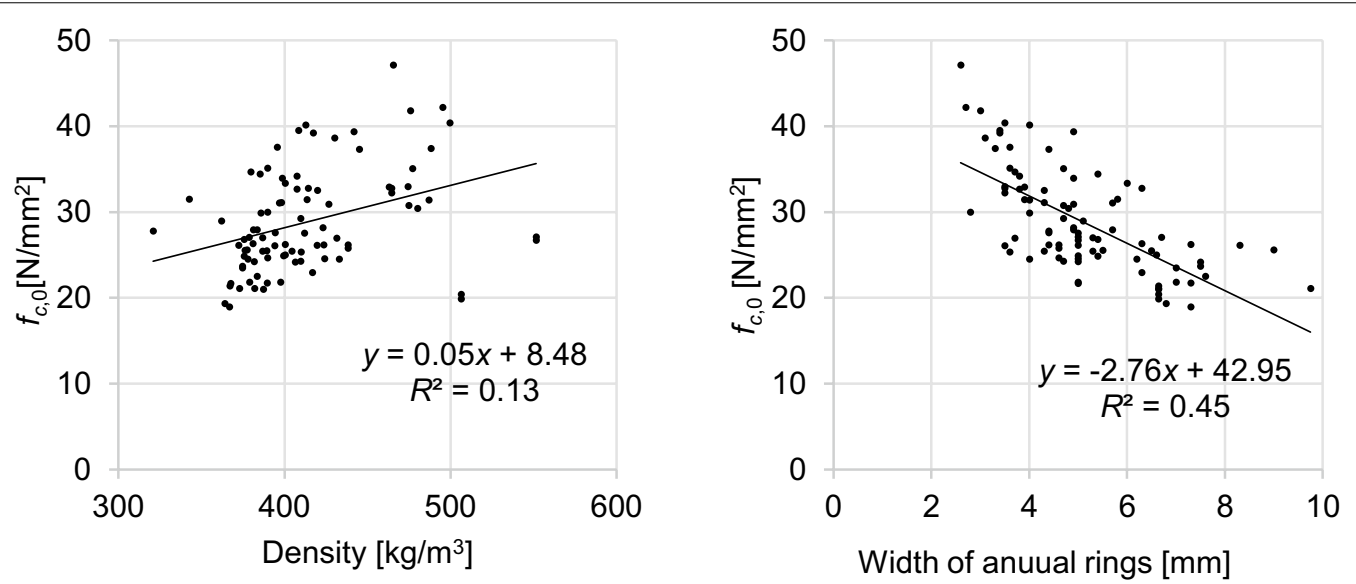

Fig. $8 f_{c, 0}$ against density and width of annual rings 

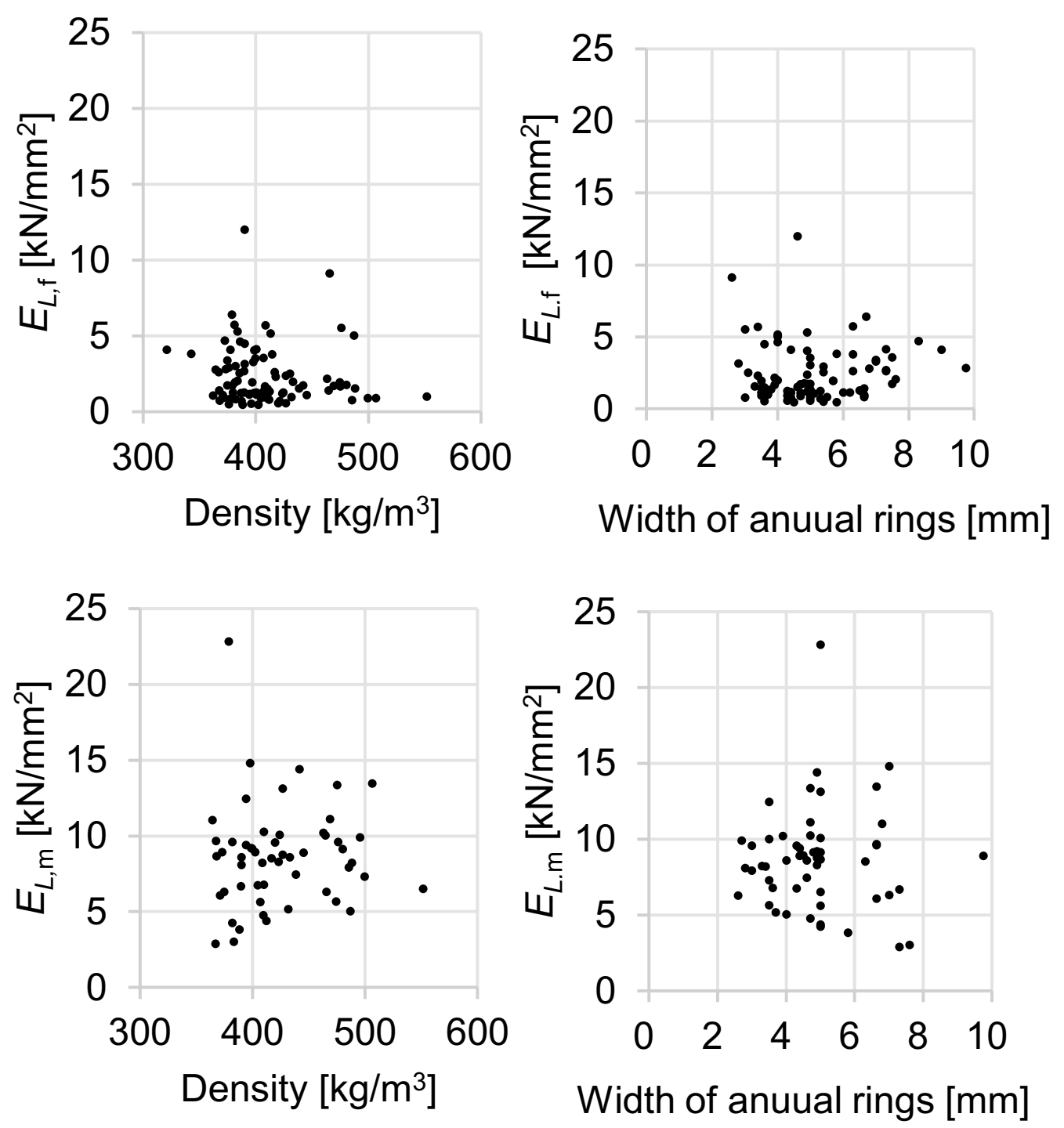

Fig. $9 E_{L, f}$ and $E_{L, m}$ against density and width of annual rings

of the loading plate which was equal to the cross-sectional area in the series "entire surface" in the compression strength. Figure 10 shows the load $(P)$-displacement $\left(\Delta l\right.$ or $\left.\Delta l_{m}\right)$ curve. The displacement $\left(\Delta l_{m}\right)$, when assuming that there is no damage zone, is given by Eq. 7:

$$
\Delta l_{m}=\varepsilon_{1} H
$$

$\Delta l_{m}$ was $1 \%-8 \% \Delta l$ in no.3-3 and $\Delta l_{m}$ was $13 \%-36 \% \Delta l$ in no.3-9. It indicates that the large portion of the deformation in full height was the deformation in the damage zone. In addition, because $E_{L, \mathrm{~m}}$ is much higher than shear modulus $G_{L T}$, it is assumed that the stress did not spread much. Thus, the compression strength loaded on the partial surface did not have the spreading effect and the spreading effect of the longitudinal modulus of elasticity was very small. However, there is a possibility that the spreading effect of the longitudinal modulus of elasticity becomes bigger in the tall specimen.

\section{Size effects of compression strength $\left(f_{c, 0}\right)$}

Size effects of the tension strength are often explained by the Weibull weakest-link theory [11]. When the Weibull weakest-link theory is applied, the statistical distribution of the test result should be Weibull distributed. To identify the distribution type fitting best the compression strength of all specimens, the three statistical distributions, normal, lognormal and Weibull were 
fitted by the Kolmogorov-Smirnov (K-S) test [12]. K-S test is a nonparametric test of the null hypothesis that the population cumulative distribution function (CDF) of the data is equal to the hypothesized CDF. The parameters of normal, lognormal and Weibull distributions were estimated by the maximum likelihood estimation (MLE) method [12]. Table 3 shows the results of estimated parameters and goodness-of-fit tests. $P$-values are defined as the probability of observing the given value of the test statistic, or greater, under the null hypothesis. Because the p-value of lognormal distribution was the biggest of the three, the K-S test indicated that the lognormal distribution was the fittest for the test result of the three. It is also recognized by Fig. 11 . Therefore, it is likely that the compression strength of the specimens does not have a size effect. The reason why compression strength of the specimens does not have a size effect unlike the report by Fryer et al. [2], is

Table 2 Mean statistics of entire or partial surface-loaded specimens, stress spreading and ratio of longitudinal modulus

\begin{tabular}{|c|c|c|c|c|c|c|c|c|c|}
\hline \multirow[t]{2}{*}{ Statistics } & \multicolumn{9}{|c|}{ Maximum stress $f_{c, 0}$} \\
\hline & $3-9$ & $3-9 p$ & 3-9pp & $6-9$ & $6-9 p$ & 6-9pp & $9-9$ & $9-9 p$ & 9-9pp \\
\hline Number $[-]$ & 6 & 6 & 6 & 6 & 6 & 6 & 6 & 6 & 6 \\
\hline Mean $\left[\mathrm{N} / \mathrm{mm}^{2}\right]$ & 30 & 27 & 27 & 29 & 29 & 26 & 28 & 27 & 27 \\
\hline \multirow[t]{2}{*}{$C V[\%]$} & 24 & 18 & 15 & 21 & 18 & 13 & 15 & 17 & 14 \\
\hline & \multicolumn{9}{|c|}{ Longitudinal modulus of elasticity in full height $E_{f}$} \\
\hline Mean $\left[\mathrm{N} / \mathrm{mm}^{2}\right]$ & 3868 & 3435 & 3731 & 2750 & 2225 & 2483 & 1249 & 1267 & 1195 \\
\hline \multirow[t]{2}{*}{ CV[\%] } & 24 & 41 & 23 & 44 & 11 & 38 & 18 & 27 & 37 \\
\hline & \multicolumn{9}{|c|}{ Stress spreading $k_{c}$} \\
\hline Mean $[-]$ & - & 0.9 & 0.9 & - & 1.0 & 0.9 & - & 1.0 & 1.0 \\
\hline \multirow[t]{2}{*}{ CV[\%] } & - & 20 & 15 & - & 10 & 13 & - & 6.3 & 3.7 \\
\hline & \multicolumn{9}{|c|}{ Ratio of longitudinal modulus $k_{E}$} \\
\hline Mean $[-]$ & - & 1.0 & 1.0 & - & 1.0 & 1.1 & - & 1.0 & 1.0 \\
\hline CV[\%] & - & 18 & 13 & - & 9.6 & 11 & - & 6.8 & 5.8 \\
\hline
\end{tabular}
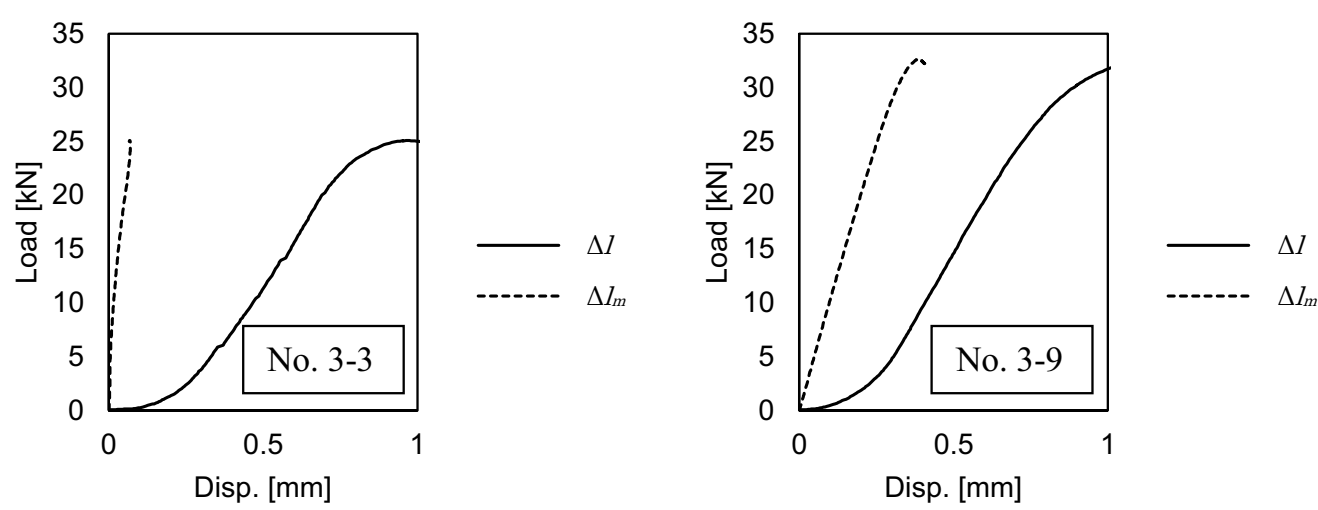

Fig. 10 Load $(P)$-displacement $\left(\Delta /\right.$ or $\left.\Delta I_{m}\right)$ curve of no.3-3 and no.3-9

Table 3 Results of estimated parameters and goodness-of-fit tests

\begin{tabular}{|c|c|c|c|c|c|c|c|c|}
\hline \multicolumn{6}{|c|}{ Parameter } & \multicolumn{3}{|l|}{$P$-value } \\
\hline \multicolumn{2}{|c|}{ Normal } & \multicolumn{2}{|c|}{ Lognormal } & \multicolumn{2}{|c|}{ Weibull } & \multicolumn{3}{|l|}{ K-S test } \\
\hline$\mu$ & $\sigma$ & $\mu$ & $\sigma$ & $a$ & $b$ & Normal & Lognormal & Weibull \\
\hline 29.5 & 6.27 & 3.36 & 0.21 & 32.1 & 4.90 & 0.095 & 0.424 & 0.073 \\
\hline
\end{tabular}

$\mu$ : mean, $\sigma$ : standard deviation, $a$ : scale parameter, $b$ : shape parameter 


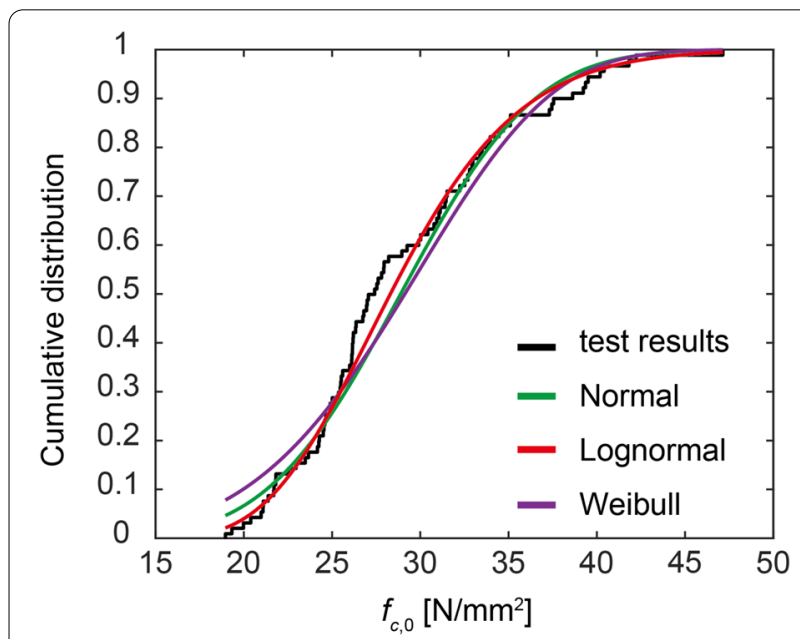

Fig. 11 Comparison of normal or Weibull distributions and tested compression strength distribution

thought that the size effect occurs due to the effect of knots and specimens of this test did not have knots.

\section{Longitudinal moduli}

The values of $E_{L, \mathrm{~m}}$ were independent of the dimensions (height and width) of the specimens as shown in Table 4, and were in close agreement with a reference value, $7350 \mathrm{~N} / \mathrm{mm}^{2}$, for the Japanese cedar [13]. Figure 12 presents the influence of the heights and the widths of the loaded area on the values of $E_{L, \mathrm{f}}$ of the series "entire surface" and "partial 1 and 2". The values of $E_{L, \mathrm{f}}$ had an increasing trend as the height decreases in the series "entire surface" or the width of the loaded area decrease in the series "entire surface" and "partial 1 and 2". Because the values of $E_{L, \mathrm{~m}}$ were independent of the dimensions, the dimensions influence on the values of $E_{L, \mathrm{f}}$ can be explained by the increasing areas of the damage zone with the increase of the widths of the loaded area. However, the areas of the damage zone do not change when the full height of the specimens increases. Martin et. al. also reported that the area of the damage zone was independent of the height of the specimens in small clear specimens $\left(20 \times 20 \mathrm{~mm}^{2}\right.$ cross-section and $30-60 \mathrm{~mm}$ high) [7]. It is presumed that the causes of changing the area of the damage zone were the surface roughness of the contact sample surface and loading plates and the fiber misalignment on the contact surface, etc. In this test, it is suggested that the specimens of large cross-sections have a larger roughness or larger fiber misalignment on the contact surface than the specimens of small crosssections. The influence of the width of the loaded area on

Table 4 Mean values and CV of longitudinal modulus of elasticity in middle zone

\begin{tabular}{|c|c|c|c|c|c|c|c|c|c|}
\hline \multirow[t]{2}{*}{ Statistics } & \multicolumn{9}{|c|}{ Longitudinal modulus of elasticity in middle zone $E_{L, m}$} \\
\hline & $3-3$ & 3-6 & $3-9$ & $6-3$ & $6-6$ & $6-9$ & $9-3$ & $9-6$ & $9-9$ \\
\hline Mean $\left[\mathrm{N} / \mathrm{mm}^{2}\right]$ & 9102 & 9253 & 8937 & 9085 & 7916 & 9032 & 10,058 & 8246 & 6481 \\
\hline CV [\%] & 20 & 28 & 29 & 31 & 23 & 32 & 65 & 41 & 34 \\
\hline
\end{tabular}
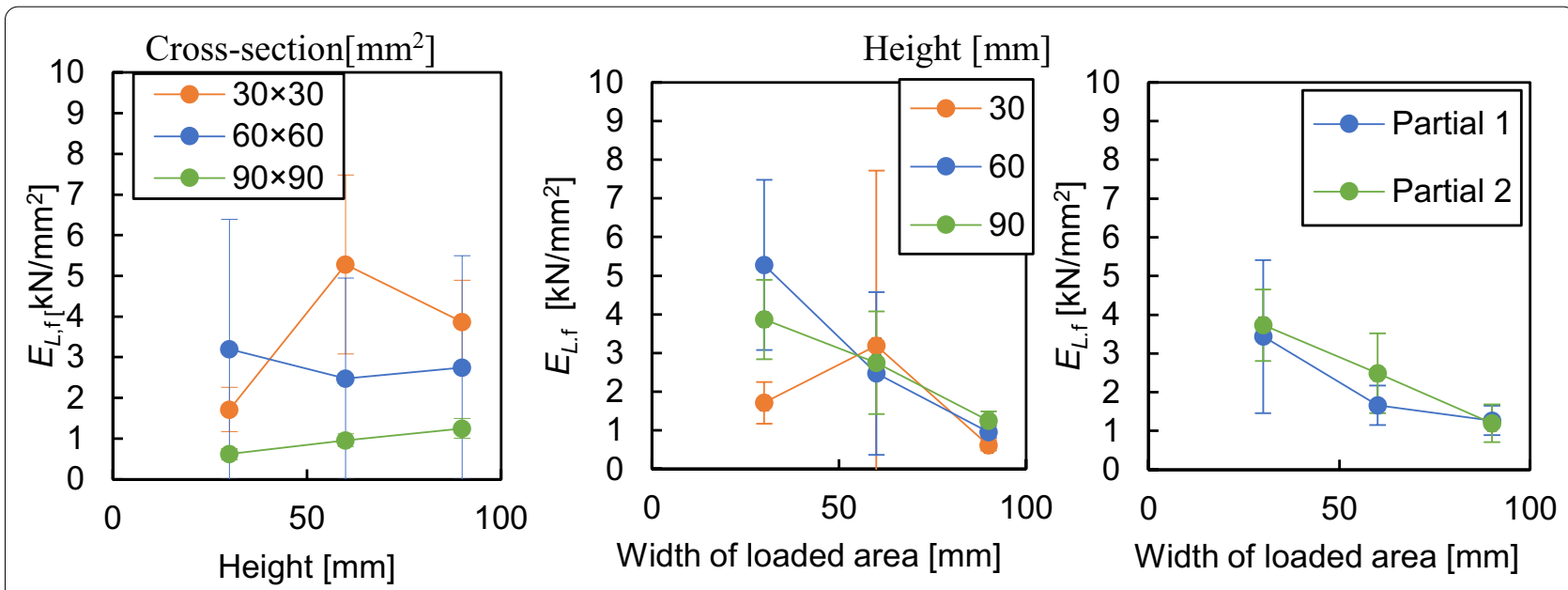

Fig. 12 Influence of heights and widths of the loaded area on values of $E_{L, f}$ of the entire and partial surface-loaded specimens 
the values of $E_{L, \mathrm{f}}$ has the possibility to change depending on cutting method and processing accuracy.

\section{Conclusion}

An experimental study on the entire and partial compression behavior parallel to the grain in solid timber specimens has resulted in a greater understanding of the material behavior as summarized below:

- Damage zones existed near the loading plates in the series "entire surface" and "partial 1 and 2".

- The density and width of annual rings have a strong impact on the value of $f_{c, 0}$. However, the values of $E_{L, \mathrm{f}}$ and $E_{L, \mathrm{~m}}$ do not correlate with the density and width of annual rings

- The spreading effect as observed for compression perpendicular to grain was not observed as pronounced in the compression parallel to the grain. The spreading effects in the compression parallel to the grain are very small and it can be suggested to ignore them for $f_{c, 0}$ and $E_{L, \mathrm{f}}$. However, there is a possibility that the spreading effect of $E_{L, f}$. becomes bigger in the tall specimen and it is a subject of future study. The partial compression strength may be able to be estimated at the compression strength with the same cross-sectional area.

- The presence of a size effect of the compression strength parallel to the grain of glulam specimens with knots was reported by Fryer et. al [2]. Meanwhile, there is a possibility that the compression strength parallel to the grain of solid wood specimens without knots does not have a size effect.

- The values of $E_{L, \mathrm{~m}}$ were independent of the dimensions of the specimens.

- $E_{L, \mathrm{f}}$ shows an increasing trend as the height decreases in the series "entire surface", and as the width of the cross-section decrease in the series "entire surface" and "partial 1 and 2". This may be because the increasing areas of the damage zone with the increase of the widths of the loaded area and the areas of the damage zone do not change when the full height of the specimens increases.

\section{Abbreviations}

Glulam: Glued laminated timber; DIC: Digital image correlation; CDF: Cumulative distribution function; MLE: Maximum likelihood estimation; K-S test: Kolmogorov-Smirnov test.

\section{Acknowledgements}

The solid wood specimens of the experiments were prepared by Aminakamokuzai. We are deeply grateful to Aminaka-mokuzai.

Part of this report was presented at the Annual Meeting of AlJ Kanto (2020), Chiba, September 2020 and will be presented at the 16th World Conference on Timber Engineering, Santiago, Republic of Chile, August 2021.

\section{Authors' contributions}

MT, KA and MI designed the experiments. MT performed the experiments, analyzed the data and was a major contributor in writing the manuscript. All authors contributed to interpretation and discussed results. All authors read and approved the final manuscript.

\section{Funding}

This work was supported by Grant-in-Aid for JSPS Research Fellow Number JP19J13253.

\section{Availability of data and materials}

The datasets used and analyzed in the current study are available from the corresponding author on reasonable request.

\section{Declarations}

\section{Competing interests}

The authors declare that they have no competing interests.

\section{Author details}

${ }^{1}$ Department of Biomaterials Sciences, Graduate School of Agricultural and Life Sciences, The University of Tokyo, 1-1-1 Yayoi, Bunkyo-ku, Tokyo, Japan. ${ }^{2}$ Department of Architecture and Civil Engineering (ACE), Division of Structural Engineering, Chalmers University of Technology, Sven Hultins gata 6, SE-412

96, Gothenburg, Sweden.

Received: 15 November 2020 Accepted: 14 May 2021

Published online: 25 May 2021

\section{References}

1. Noguchi M, Nakamura N, lijima Y (2011) Manual calculation method of embedment stiffness of partial compression parallel to the grain and its strength properties. J Struct Constr Eng (AIJ) 76(662):803-809

2. Fryer BK, Foster RM, Ramage MH (2018) Size effect of large scale timber columns. In: Proceedings of the 12th WCTE, Seoul, Korea, Press Republic of Korea, vol 7, 20-23 August 2018

3. Choi D, Thorpe JL, Hanna RB (1991) Image analysis to measure strain in wood and paper. Wood Sci Technol 25:251-262. https://doi.org/10. 1007/BF00225465

4. Dahl KB, Malo KA (2009) Planar strain measurements on wood specimens. Exp Mech 49:575-586. https://doi.org/10.1007/ s11340-008-9162-0

5. Zink AG, Davidson RW, Hanna RB (1995) Strain measurement in wood using a digital image correlation technique. Wood Fiber Sci 27(4):346-359

6. Xavier J, de Jesus AMP, Morais JJL, Pinto JMT (2011) Stereovision measurements on evaluating the modulus of elasticity of wood by compression tests parallel to the grain. Constr Build Mater 26(1):207-215. https://doi.org/10.1016/j.conbuildmat.2011.06.012

7. Martin B, Jan T, Václav S, Jaromír M, Peter R (2015) Standard and nonstandard deformation behavior of European beech and Norway spruce during compression. Holzforschung 69(9):1107-1116. https://doi.org/ 10.1515/hf-2014-0231

8. GOM Correlate (GOM mbH, Germany), http://www.gom.com/3d-softw are/gom-correlate.html. Accessed 10 May 2021 
9. Leijten AJM, Franke S, Quenneville P, Gupta R (2012) Bearing strength capacity of continuous supported timber beams: unified approach for test methods and structural design codes. J Struct Eng. https://doi.org/ 10.1061/(ASCE)ST.1943-541X.0000454

10. van der Put TACM (2008) Derivation of the bearing strength perpendicular to the grain of locally loaded timber blocks. Holz Roh Werkst 66:409-417. https://doi.org/10.1007/s00107-008-0258-0

11. Weibull W (1939) A statistical theory of the strengths of materials. Ingeniors Etanskaps Akademien-Handlingar 151:1-45
12. Matlab online help. http://www.mathworks.com. Accessed 10 May 2021

13. Forestry and Forest Products Research Institute (2004) Wood Industry Handbook. Maruzen, Tokyo

\section{Publisher's Note}

Springer Nature remains neutral with regard to jurisdictional claims in published maps and institutional affiliations.

\section{Submit your manuscript to a SpringerOpen ${ }^{\circ}$ journal and benefit from:}

- Convenient online submission

- Rigorous peer review

- Open access: articles freely available online

- High visibility within the field

- Retaining the copyright to your article

Submit your next manuscript at $\boldsymbol{\nabla}$ springeropen.com 